\title{
Vásquez Delgado, T. (2015). Territorios, Conflicto Armado y Política en el Caquetá: 1900-2010. Bogotá: Uniandes.
}

Por Estefanía Ciro ${ }^{1}$

I Centro de Investigación y Educación Popular, Cinep/PPP, y el
Observatorio Colombiano para el Desarrollo Integral, la Convi-
vencia Ciudadana y el Fortalecimiento Institucional, Odecofi, han
liderado una agenda de investigación prolífica en el estudio de la vio-
lencia política, la formación del Estado y el conflicto. Dicha agenda
plantea que el conflicto armado en Colombia no ha sido homogéneo ni
en el tiempo ni en el espacio, y en la misma medida propone que los
actores armados no se desenvuelven en territorios vacíos. Con sus tra-
bajos, tanto el Cinep/PPP como Odecofi, han contribuido a una profun-
da reflexión sobre el Estado y su proceso de construcción al confrontar
las formas tradicionales de estudiarlo como un fin teleológico, un ente
homogéneo, monolítico y universal².

Bajo esta agenda de investigación, la configuración regional y su articulación con los procesos nacionales y la construcción del Estado tienen una atención particular. Son elementos fundamentales a la hora de comprender cómo se constituye el accionar de los grupos armados

1 Doctora del Programa de Ciencias Políticas y Sociales de la Universidad Nacional Autónoma de México.

2 Un libro que recoge el trabajo individual y las reflexiones nutridas a partir de este equipo de trabajo es Poder y violencia en Colombia (2014), de Fernán González. 
y del Estado mismo, pues esto determina el desarrollo del conflicto en el país. Uno de los ejemplos interesantes de este abordaje es la más reciente publicación de Teófilo Vásquez, Territorios, Conflicto Armado y Política en el Caquetá: 1900-2010.

Este libro estudia la construcción territorial del piedemonte caqueteño en la Amazonía colombiana y su relación con el conflicto armado. Para esto propone una aproximación teórica al problema basada en tres tipos de trayectorias. En primer lugar, están los territorios estructurados por la guerra, los cuales hacen referencia a aquellos donde el conflicto ha sido central en la configuración identitaria y social de la región, y donde el actor armado ha sido fundamental en la regulación de estos territorios. En segundo lugar se encuentran los territorios en disputa, donde el proceso de construcción territorial y configuración social fue anterior a la inserción del conflicto armado; razón por la cual los actores armados no lograron tener un papel preponderante en el control de la población de estos territorios. Y por último están los territorios integrados, que son los centros de la actividad económica y política del país, es decir, del Estado colombiano; razón por la cual la presencia de los actores armados en estos es esporádica.

A lo largo de cuatro capítulos este texto de Vásquez expone cómo se configura el piedemonte caqueteño, y cómo, durante el siglo XX, aparecen diversas subregiones en el Caquetá entre las cuales está El Caguán. El análisis de estas dos territorialidades, la que se estructura en torno a San Vicente del Caguán y la que lo hace sobre Cartagena del Chairá, se hace a partir de sus diversos procesos de poblamiento, sus estructuras agrarias, las identidades políticas y las dinámicas del conflicto armado.

El libro señala que una subregión que se constituye en torno San Vicente es un territorio en disputa, pues allí se ha consolidado una economía ganadera basada en la producción tanto de la leche como de la carne. Esto redundó en la formación de una élite regional que sirvió como mediadora ante el Huila y el resto del país. Más que un espacio de control 
de las Farc-Ep, lo que sucede en esta zona es una disputa constante por territorio entre este grupo armado y el Estado.

El medio y bajo Caguán es un territorio estructurado por la guerra donde el proceso colonizador permanece activo; proceso que, además, está fuertemente influido por la economía de la coca. Su adscripción política es principalmente de izquierda y es donde las Farc-Ep han asumido el papel de mediador político y regulador social y económico. Esta región ha sido disputada esporádicamente por el Estado quien ha ido en contra del orden insurgente.

Territorios, Conflicto Armado y Política en el Caquetá es un libro que contribuye notablemente tanto a la investigación regional como al conjunto de análisis que buscan comprender el conflicto en el país. En relación con la historiografía regional, detrás de esta investigación hay un meritorio y detallado esfuerzo por teorizar el asunto del conflicto en el país, lo cual hace parte del creciente interés de la academia por estudiar al Caquetá ${ }^{\text {. }}$

Como parte de este proceso, Vásquez construye un puente entre los estudios regionales y la literatura nacional e internacional sobre Estado y los territorios en guerra. Su propuesta se basa en las investigaciones de María Teresa Uribe acerca de las territorialidades belicosas, así como

Un conjunto de trabajos son un ejemplo de este interés como los de Nicolás Espinosa, Alejandra Ciro y Diana Guerra. Sobre la relación de los campesinos con la guerrilla en la vida cotidiana de la guerra Nicolás Espinosa (2006). "Violencia y vida campesina”. Revista Colombiana de Sociología. 27, 151-168 (2006). Alejandra Ciro. Unos grises muy verracos. Poder político local y configuración del Estado en el Caquetá 1980-2006. Tesis de Maestría. (Bogotá: Instituto de Estudios Políticos y Relaciones Internacionales de la Universidad Nacional de Colombia, 2009). Diana Moreno, "El Estado somos nosotros": Prácticas organizativas comunitarias de la zona rural de San Vicente del Caguán- Caquetá, como materialización de la construcción del Estado local en Colombia. Tesis Maestría. (Bogotá: Departamento de Antropología. Universidad de los Andes, 2015). 
también tiene en cuenta estudios de Clara Inés García en relación con las identidades territoriales y el conflicto. El autor profundiza su agudo análisis retomando postulados de Stathis Kalyvas sobre los análisis subnacionales de la guerra y el examen de las lógicas de la violencia a nivel local; y en ese mismo sentido retoma a Charles Tilly acerca del estudio de los regímenes, la violencia y la intermediación política a nivel local ${ }^{4}$. Este libro es una reflexión de mayor aliento basada en anteriores trabajos del autor, como Violencia política en Colombia: De la nación fragmentada a la construcción del Estado (2003) y Una vieja guerra en un nuevo contexto: conflicto y territorio en el sur de Colombia $(2011)^{5}$.

Entre las fuentes que apoyan este libro de Teófilo Vásquez se encuentran, por un lado, estadísticas demográficas, electorales y del conflicto en la región; y, por otro, un valioso trabajo cualitativo que consistió en entrevistas y talleres en el Caquetá que iniciaron durante la negociaciones de El Caguán hasta este reciente periodo pos Plan Colombia. Leer el libro es efectivamente constatar que esta zona no es un territorio vacío pues las voces de sus pobladores, basadas en memorias de los colonos o en entrevistas a líderes sociales y políticos, están presentes a lo largo de los capítulos.

De otro lado, este libro estableció una dialéctica entre la teoría y las apuestas académicas, lo cual le otorga un valor particular; en ese sentido es muy valiosa la apuesta interdisciplinar que pone en dialogo estudios de la Geografía, la Ciencia Política y la Historia. Esto le permite al autor resaltar la complejidad de los procesos de construcción territorial dentro

4 Sobre territorialidades belicosas: María Teresa Uribe (2001). Sobre identidades territoriales y conflicto: Clara Inés García (2009). Sobre los análisis subnacionales de la guerra y el examen de las lógicas de la violencia a nivel local: Stathis Kalyvas (2010). Sobre estudios de los regímenes, la violencia y la intermediación política: Charles Tilly (1992).

5 González, F., Bolívar, I. y Vásquez, T. (2003). Violencia política en Colombia: de la nación fragmentada a la construcción del Estado. Bogotá: Cinep. / Vásquez, T., Vargas, A. y Restrepo, J. (2011). Una vieja guerra en un nuevo contexto: Conflicto y territorio en el sur de Colombia. Bogotá: Pontificia Universidad Javeriana. 
del departamento del Caquetá, y a la vez articularlo con un análisis de la cuestión agraria y la mediación política local, lo que involucra la formación de élites regionales y al Estado.

En particular, el análisis geográfico del problema discute la idea de un territorio caqueteño (homogéneo, ahistórico, inmutable), y lo expone como un espacio de tensiones, apropiado, cambiante y diverso. Por ejemplo, el río Caguán, que nace en el piedemonte, no es un elemento estático en un mapa sino que la relación de la población con el río los ubica espacialmente (ir "río arriba” o "río abajo") y compone diferentes subregiones: el alto Caguán en contraposición con el medio y bajo Caguán, dos de las territorialidades contrastadas.

Un reto para la academia ha sido comprender el papel de la economía de la coca en el conflicto, y este es un tema ineludible en el estudio del conflicto en el Caquetá. En el libro de Vásquez este es un debate trasversal mencionado en torno a las nuevas y las viejas guerras. Autores como Paul Collier han explicado las nuevas guerras y los mercados de la violencia como una lucha por los recursos por parte de los diferentes actores armados . Por su parte, Vásquez, en Territorios, Conflicto Armado y Política en el Caquetá: 1900-2010, plantea que el conflicto colombiano no se puede considerar bajo esta dicotomía -ideología y recursos-, pues sus raíces parten de una división ideológica que en las últimas décadas se han imbricado en una competencia por recursos por parte de los actores involucrados. También, reflexionar sobre la naturaleza de esta guerra permite en el caso del Caquetá ver a los campesinos más allá de simples “títeres o auxiliadores de la guerrilla”, y al conflicto como exclusivamente económico. Así, se ponen sobre la mesa temas como el de las obediencias, la legitimidad de los actores (guerrilla y Estado) y las maneras en que se experimentan la múltiples "legalidades" de estos órdenes en dicho territorio. Como afirma el autor, "no es una tierra sin ley sino, por el contrario, el campesino caqueteño vive en medio de multiplicidad de regulaciones en disputa” (p.). 
Hace treinta años aproximadamente se publicó Colonización, Coca y Guerrilla (1986), texto que reseñó los conflictos que se cernían sobre el territorio en torno a la aparición de los cultivos de coca en el contexto de los diálogos del gobierno de Betancur con esta guerrilla en la década de los ochenta. Coincidencialmente, el libro de Vásquez también se publica en un escenario de negociación de paz (2015). Su epílogo en particular se convierte en un documento central en el análisis de los retos del pos-acuerdo. En esa dirección debe decirse, entonces, que es un libro que no solo da luces sobre un camino a partir de un estudio experto y serio, sino también trasgrede el papel tradicional del investigador social y de su obra en relación con su objeto de estudio y con su tiempo. Este libro proponer, arriesgadamente, conceptos como los de la dimensión territorial de la paz, a la vez que plantea hacer un balance de lo que se juega en La Habana y los retos del pos-acuerdo en regiones afectadas y directamente involucradas en la guerra, como es la zona del Caquetá.

Fue por mucho tiempo un hábito de pensamiento asumir al Caquetá como un territorio vacío. Algo similar ocurre con la investigación social sobre esta región: tanto quejarnos de su "abandono" da la impresión de que no hay nada escrito, lo cual es una suposición equivocada. Poco a poco se consolida una serie de rigurosos y novedosos trabajos, como este de Teófilo Vásquez, que le han apostado con calidad a la exigencia de comprender a esta región y los retos que enfrenta.

\section{Publicaciones periódicas}

Collier, P. (2001). “Causas Económicas de las guerras civiles y sus implicaciones para el diseño de las políticas”. En El Malpensante, $n^{\circ} 30$.

Espinosa, N. (2006). "Violencia y vida campesina”. En Revista Colombiana de Sociología, n²7. 151-168.

Díaz, A. M. y Sánchez, F. (2004). "Geografía de los cultivos ilícitos y conflicto armado en Colombia”. En Documento Cede 18. Bogotá: Universidad de los Andes. 


\section{Libros y tesis}

Ciro, A. (2009) Unos grises muy verracos. Poder político local y configuración del Estado en el Caquetá 1980-2006. (Tesis de Maestría en Estudios Políticos y Relaciones Internacionales). Bogotá: Universidad Nacional de Colombia.

García, C. (2001) "Nuevo enfoque para el análisis regional: elementos para la discusión”. En García, C.I., y Aramburo, C.I. (eds.) Universos socioespaciales: Procedencias y destinos. Bogotá: Universidad de Antioquia.

González, F. (2004) Poder y violencia en Colombia. Bogotá: Odecofi, CinepPPP, Colciencias.

González, F., Bolívar, I. \& Vásquez, T. (2003) Violencia política en Colombia: de la nación fragmentada a la construcción del Estado. Bogotá: Cinep-PPP.

Kalyvas, S. (2010). La lógica de la violencia en la guerra civil. Madrid: Akal.

Moreno, D. (2015). El Estado somos nosotros": Prácticas organizativas comunitarias de la zona rural de San Vicente del Caguán- Caquetá, como materialización de la construcción del Estado local en Colombia. (Tesis de Maestría en Antropología). Bogotá: Universidad de los Andes.

Tilly, C. (1992) Coerción, capital y los Estados europeos, 990-1990. Madrid: Alianza.

Uribe, M. (2001). Nación, ciudadano y soberano. Medellín: Corporación Región.

Vásquez, T., Vargas, A., \& Restrepo, J. (2011) Una vieja guerra en un nuevo contexto: Conflicto y territorio en el sur de Colombia. Bogotá: Pontificia Universidad Javeriana. 